\title{
Mental Health of the Refugee and Native Patients with End-Stage Renal Diseases Receiving Hemodialysis During COVID-19 in Istanbul: A Cross-Sectional Study from a Tertiary Center
}

\author{
๑ Murat Yalcin, ๑ Yagmur Bashan*, • Selim Arpacioglu** , • Hakan Karas*** , \\ (-) Egemen Cebeci* \\ University of Health Sciences Turkey, Erenkoy Mental and Nervous Diseases Training and Research Hospital, Clinic of Psychiatry, Istanbul, Turkey \\ *University of Health Sciences Turkey, Haseki Training and Research Hospital, Clinic of Nephrology, Istanbul, Turkey \\ **Altinbas University, Faculty of Medicine, Department of Psychiatry, Istanbul, Turkey \\ ***Istanbul Gelisim University Faculty of Economic Administrative and Social Sciences, Department of Psychology, Istanbul, Turkey
}

\section{Abstract}

\begin{abstract}
Aim: Patients receiving hemodialysis (HD) are at high risk for developing psychiatric symptoms. The aim of this study is to investigate the levels and correlates of depression, anxiety, somatization and post-traumatic stress disorder (PTSD) symptoms of refugee HD patients and compare to native HD patients.

Methods: This is a descriptive study with a cross-sectional design. A total of 58 refugee $(n=27)$ and native $(n=31)$ end-stage renal disease patients receiving HD were included. The data were collected between $14^{\text {th }}$ and $16^{\text {th }}$ of July 2021 . Patient health questionnairesomatic, anxiety, and depressive symptoms (PHQ-SADS) scales and posttraumatic-stress disorder checklist for DSM-5 (PCL-5) were used for the clinical assessment.

Results: Refugee patients had similar sociodemographic, clinical and HD characteristics with native patients. Anxiety subscale and PCL5 scores were significantly higher in refugee patients ( $p=0.04$ and $p=0.03$, respectively), while depression and somatization subscales levels did not differ among groups. The age was negatively correlated with depressive symptom levels in refugee patients while somatic symptom levels were positively correlated with depression, anxiety and PTSD symptom levels in both groups.

Conclusion: The staff of HD centers should be trained in order to recognize psychiatric disorders and symptoms, and routine psychiatric assessment may contribute to improving the mental health and preventing adverse health outcomes in refugee HD patients.
\end{abstract}

Keywords: Renal dialysis, refugees, depression, mental health, COVID-19

\section{Introduction}

In consequence of the compelling treatment schedule, dietary restrictions, and impairment in physical and sexual functioning, living on hemodialysis (HD) is a perpetually challenging condition for patients with end-stage renal disease (ESRD) (1,2). Accordingly, depressive and anxiety disorders are the two most frequent psychiatric disorders in HD patients, the prevalence of depression and anxiety symptoms in HD patients are reported to be higher than the general population and range from $37 \%$ to $42 \%$ and from $38 \%$ to $53 \%$, respectively (3). These two psychiatric conditions commonly co-occur but are frequently underdiagnosed and untreated, whereas both disorders were reported to be closely associated with poor treatment compliance and outcome, hospitalization, impaired quality of life and mortality in this population (3-6). Considering the Coronavirus disease-2019 (COVID-19) pandemic, the uncertainty and health-related anxiety could also increase

Address for Correspondence: Murat Yalcin, University of Health Sciences Turkey, Erenkoy Mental and Nervous Diseases Training and Research Hospital, Clinic of Psychiatry, Istanbul, Turkey Phone: +90 5056369060 E-mail: muratyalcin@gmail.com ORCID: orcid.org/0000-0002-1129-8960 Received: 26.07.2021 Accepted: 17.09.2021 
the severity of mental disorders or may cause new-onset mental disorders in ESRD patients as individuals with severe chronic illnesses have higher rates of morbidity and mortality rates due to COVID-19 $(7,8)$.

In the last decade, a total of 13 million refugees have been displaced due to the Syrian civil war in the Middle East (9). As of 2021, Turkey is the country hosting the largest number of refugees under "temporary protection" with approximately 3,6 million refugees, and many of those had to experience difficulties such as accessing health and social services, uncertainty around their legal rights, lack of social support, unemployment, financial issues, social isolation and xenophobia after forced migration $(10,11)$. Therefore, post-traumatic stress disorder (PTSD) and other psychiatric conditions including depression, anxiety and somatization were reported to be at higher rates among refugees and have been found to persist over many years (12-14). As one of the most disadvantageous groups in society, refugees with ESRD could be expected to be highly vulnerable to psychological distress during the COVID-19 pandemic, as this population could be more adversely affected by negative consequences of the pandemic such as social isolation, economic hardship and unemployment, as well as uncertainty and health related anxiety (15). However, to date, there are still scant data before and during the COVID-19 pandemic on whether refugee HD patients have a higher risk of developing psychiatric symptoms than native HD patients. To the best of our knowledge, there are only two studies focusing on the mental health of refugee ESRD patients receiving $\mathrm{HD}(16,17)$.

This study set out to determine the mental health status of refugee and native ESRD patients receiving HD during the COVID-19. Our aim is to investigate and compare the levels of depression, anxiety, somatic anxiety and PTSD symptoms of refugee and native HD patients and we hypothesized that HD dependent ESRD patients have high comobidity of comorbidity of psychiatric conditions and refugee HD patients have higher depression, anxiety, somatic anxiety and PTSD levels compared to the native HD patients during the COVID-19.

\section{Methods}

\section{Study Design and Sample}

The study was conducted in accordance with the Declaration of Helsinki and its later amendments. Ethics committee approval was obtained from University of Health Sciences Turkey, Haseki Training and Research Hospital Ethics Committee (approval number: 2021-59) and COVID-19 Scientific Review Board of Ministry of Health of the Republic of Turkey. This study is a cross-sectional study conducted in a tertiary center, which enrolled 69 refugee and native patients who were receiving HD in the HD Center of University of Health Sciences Turkey, Haseki
Training and Research Hospital, which which a have a high percentage of refugee dialysis patients. The term "native" was used to describe native Turkish patients. The data of the study were collected between 14 and 16 July 2021 . Patients younger than 18 and older than 75 years old, those with history of HD less than three months, those undergoing home HD, those who were not able to fill out questionnaires in Turkish and Arabic language, those with intellectual disability that would limit the ability to answer the questionnaires and those who refused to give informed consent were excluded from the study. Finally, a total of 58 adult patients, consisting of 27 Syrian refugees and 31 native patients receiving $\mathrm{HD}$, who met the study criteria and gave informed consent, were included in the study.

\section{Sociodemographic and Clinical Questionnaire}

This questionnaire was prepared by the researchers for this study. The following demographic and clinical data were extracted from from the electronic records: Age, gender, education level, comorbidity, primary cause of kidney disease, duration of $H D$, residual renal functions, urea reduction rate, vascular access route, $\mathrm{Kt} / \mathrm{V}$, and also hemoglobin, albumin, urea and creatinine levels obtained at the beginning of July 2021 . The data including monthly household income per capita, the number of people living together and duration of refugee status were obtained from the participants.

Patient Health Questionnaire-Somatic, Anxiety, and Depressive Symptoms (PHQ-SADS)

Patient health questionnaire-somatic, anxiety, and depressive symptoms (PHQ-SADS) is a self-administrated tool designed to measure the rates of psychiatric morbidity (18). The scales can be applied together or separately as PHQ-15 (somatization), GAD-7 (anxiety), PHQ-9 (depression), and 5-item panic modules. Cut-off scores of 5, 10 and 15 represent mild, moderate and severe symptom levels on all three scales. Validated forms in Turkish and Arabic language were used for the refugee and native patients $(19,20)$.

\section{Posttraumatic Stress Disorder Checklist for DSM-5} (PCL-5)

The PCL-5 is a 20-item self-report scale developed to assess the severity of PTSD symptoms of DSM-5 (21). The rating scale ranges between 0 (not at all) and 4 (extremely) for each symptom. A cut-off value of $\geq 31$ was suggested by the authors as the optimal PCL-5 score for PTSD diagnosis. Validated forms in Turkish and Arabic languages were used for the refugee and native patients $(22,23)$.

\section{Statistical Analysis}

The analyses were performed using the IBM SPSS Statistics for Windows, Version 25.0 (IBM Corp., Armonk, NY, USA). Descriptive statistics were expressed as numbers 
and percentages for categorical variables and as mean, standard deviation for numerical variables. The conformity of variables to normal distribution was assessed using visual (histogram and probability graphs) and analytical methods (Kolmogorov-Smirnov/Shapiro-Wilk tests). The chi-square test was used for two-group comparisons of categorical variables. For the comparison of two and multiple groups the Mann-Whitney $U$ and Kruskal-Wallis tests were used for the comparison of quantitative data, respectively. Spearman's rho correlation coefficients were used for correlation analysis. A p-value of less than 0.05 was considered statistically significant.

\section{Results}

There was no significant difference between refugee and native patients regarding; age, gender, education level, primary cause of kidney disease, monthly household income per capita, the number of people living together, duration of $H D$, residual renal functions, vascular access route, hemoglobin, albumin, $\mathrm{Kt} / \mathrm{V}$, urea and creatinine levels ( $p>0.05)$. The data regarding sociodemographic, clinical and HD characteristics are provided in Table 1.

The comparison of PHQ-9, GAD-7, PHQ-15 and PCL5 between refugee and native $\mathrm{HD}$ patients indicated

Table 1. Characteristics of the refugee and native patients receiving HD

\begin{tabular}{|c|c|c|c|c|}
\hline Characteristics & & $\begin{array}{l}\text { Refugee } \\
\text { patients } \\
(\mathrm{N}=27)\end{array}$ & $\begin{array}{l}\text { Native } \\
\text { patients } \\
(\mathrm{N}=31)\end{array}$ & p \\
\hline \multicolumn{5}{|l|}{ Demographic and clinical characteristics } \\
\hline \multicolumn{2}{|l|}{ Age, mean $\pm S D$} & $48.0 \pm 15.2$ & $49.5 \pm 15.8$ & $0.62^{*}$ \\
\hline Gender, n (\%) & $\begin{array}{l}\text { Male } \\
\text { Female }\end{array}$ & $\begin{array}{l}12 \%(44.4) \\
15 \%(55.6)\end{array}$ & $\begin{array}{l}17 \%(54.8) \\
14 \%(45.2) \\
\end{array}$ & $0.43^{* *}$ \\
\hline \multirow{4}{*}{ Education status, n (\%) } & Illiterate & $4 \%(14.9)$ & $2 \%(6.5)$ & \multirow{4}{*}{$0.12^{* * *}$} \\
\hline & Primary school & $12 \%(44.4)$ & $13 \%(41.9)$ & \\
\hline & High school & $6 \%(22.2)$ & $9 \%(29)$ & \\
\hline & Graduate school & $5 \%(18.5)$ & $7 \%(22.6$ & \\
\hline \multirow{6}{*}{ Primary kidney disease, $\mathrm{n}(\%)$} & Diabetic kidney disease & $8 \%(29.6)$ & $10 \%(32.3)$ & \multirow{6}{*}{$0.78^{* * *}$} \\
\hline & Hypertensive nephrosclerosis & $7 \%(25.9)$ & $9 \%(29)$ & \\
\hline & Glomerulonephritis & $1 \%(3.7)$ & $1 \%(3.2)$ & \\
\hline & $\begin{array}{l}\text { Autosomal dominant polycystic } \\
\text { kidney disease }\end{array}$ & $0 \%(0)$ & $1 \%(3.2)$ & \\
\hline & Others & $2 \%(7.4)$ & $4 \%(12.9)$ & \\
\hline & Unknown & $9 \%(33.3)$ & $6 \%(19.4)$ & \\
\hline Presence of residual renal function, $\mathrm{n}(\%)$ & - & $11 \%(40.7)$ & $13 \%(41.9)$ & $0.96^{\star \star}$ \\
\hline The number of people living together, mean \pm SD & - & $6.1 \pm 1.8$ & $4.1 \pm 1.8$ & $<0.001^{*}$ \\
\hline $\begin{array}{l}\text { Monthly household income per capita (Turkish Liras), mean } \\
\pm \text { SD }\end{array}$ & - & $603 \pm 337$ & $568 \pm 307$ & $0.89 *$ \\
\hline Duration of refugee status (year) & - & $7.3 \pm 1.2$ & - & - \\
\hline \multicolumn{5}{|l|}{ Hemodialysis characteristics } \\
\hline \multirow{3}{*}{ Hemodialysis frequency, $\mathrm{n}(\%)$} & Once weekly & $1 \%(3.7)$ & $1 \%(3.2)$ & \multirow{3}{*}{$0.97^{\star * \star}$} \\
\hline & Twice weekly & $3 \%(11.1)$ & $4 \%(12.9)$ & \\
\hline & Thrice weekly & $23 \%(85.2)$ & $26 \%(83.9)$ & \\
\hline Duration of hemodialysis (year), mean \pm SD & - & $4.4 \pm 4.3$ & $3.7 \pm 3.6$ & $0.44^{*}$ \\
\hline \multirow{2}{*}{ Vascular access, $\mathrm{n}(\%)$} & Arteriovenous fistula & $24 \%(88.9)$ & $24 \%(77.4)$ & \multirow{2}{*}{$0.24^{\star *}$} \\
\hline & Tunneled catheter & $3 \%(11.1)$ & $7 \%(22.6)$ & \\
\hline $\mathrm{Kt} / \mathrm{V}$, mean $\pm \mathrm{SD}$ & - & $1.82 \pm 0.34$ & $1.77 \pm 0.54$ & $0.38^{*}$ \\
\hline Urea reduction rate $(\%)$, mean \pm SD & - & $76 \pm 6$ & $76 \pm 7$ & $0.43^{*}$ \\
\hline Initial serum creatinine $(\mathrm{mg} / \mathrm{dL})$, mean $\pm \mathrm{SD}$ & - & $8.2 \pm 2.3$ & $7.1 \pm 2.3$ & $0.09 *$ \\
\hline Initial serum urea $(\mathrm{mg} / \mathrm{dL})$, mean $\pm \mathrm{SD}$ & - & $123 \pm 28$ & $132 \pm 36$ & $0.29 *$ \\
\hline Albumin $(\mathrm{g} / \mathrm{dL})$, mean $\pm \mathrm{SD}$ & - & $3.6 \pm 0.6$ & $3.9 \pm 0.6$ & $0.24^{*}$ \\
\hline Hemoglobin $(\mathrm{g} / \mathrm{dL})$, mean $\pm \mathrm{SD}$ & - & $9.8 \pm 1.8$ & $9.9 \pm 1.4$ & $0.91^{*}$ \\
\hline
\end{tabular}


that GAD-7 and PCL-5 scores were significantly higher in refugee patients ( $p<0.05$ for both) while PHQ-9 and PHQ15 scores did not differ among groups. The data regarding the comparison of the scales between refugee and native patients are provided in Table 2.

When the participants were investigated regarding the symptom severity of psychiatric disorders using suggested cut-off values of the scales; depression and somatic anxiety were found to be the most frequent psychiatric conditions (29.3\% for each). Among refugees, somatic anxiety and PTSD were the most frequent psychiatric conditions (33.3\% for each), while depression was more frequent among the native patients. The data regarding the symptom severity of depression, anxiety, somatic anxiety and PTSD are provided in Table 3.

Regarding the correlates of PHQ-9, GAD-7 and PCL5 in refugee and native HD patients; there was a strong negative correlation between the age and PHQ-9 scores in refugee patients $(r=-0.611 ; p<0.01)$. Duration of refugee status had a moderate and positive correlation with PHQ9 scores in the refugee group $(r=0.475, p<0.05)$. Somatic anxiety had a strong positive correlation with PHQ-9 scores in both refugee and native patients $(r=0.737 ; p<0.001$; $r=0.650, p<0.001$, respectively); strong positive correlation with GAD-7 scores in refugees $(r=600, p<0.01)$ and weak positive correlation with GAD-7 $(r=0.381, p<0.05)$ in native patients; and moderate positive correlation with PCL-5 scores in refugee patients $(r=0.419, p<0.05)$ and weak

\begin{tabular}{|l|l|l|l|}
\hline \multicolumn{4}{|l|}{$\begin{array}{l}\text { Table 2. Comparison of depression, anxiety, somatic anxiety and } \\
\text { PTSD levels between refugee and native patients receiving HD }\end{array}$} \\
\hline Scales & $\begin{array}{l}\text { Refugee } \\
\text { patients } \\
(\mathbf{n}=\mathbf{2 7})\end{array}$ & $\begin{array}{l}\text { Native } \\
\text { patients } \\
(\mathbf{n}=\mathbf{3 1})\end{array}$ & $\mathbf{p}$ \\
\hline PHQ-9 & $5.96 \pm 5.11$ & $7.29 \pm 5.19$ & $0.32^{*}$ \\
\hline GAD-7 & $7.20 \pm 3.89$ & $4.83 \pm 4.54$ & $\mathbf{0 . 0 4}{ }^{*}$ \\
\hline PHQ-15 & $7.71 \pm 4.43$ & $7.32 \pm 4.53$ & $0.75^{*}$ \\
\hline PCL-5 & $26.65 \pm 15.84$ & $16.52 \pm 13.09$ & $\mathbf{0 . 0 3 *}$ \\
\hline $\begin{array}{l}\text { *Mann-Whitney U test, PHQ-9: Patient health questionnaire-9, } \\
\text { GAD-7: Generalized anxiety disorder-7, PHQ-15: Patient health } \\
\text { questionnaire-15, PCL-5: Posttraumatic stress disorder checklist for } \\
\text { DSM-5, Bold print indicates statistical significance at 0.05 level }\end{array}$ \\
\hline
\end{tabular}

\begin{tabular}{|c|c|c|}
\hline Symptom severity & $\begin{array}{l}\text { Refugee patients } \\
(n=27)\end{array}$ & $\begin{array}{l}\text { Native patients } \\
(n=31)\end{array}$ \\
\hline PHQ-9 $\geq 10$ & $6(22.2 \%)$ & $11(35.4 \%)$ \\
\hline GAD-7 $\geq 10$ & $8(29.6 \%)$ & $4(12.9 \%)$ \\
\hline PHQ-15 $\geq 10$ & $9(33.3 \%)$ & $8(25.8 \%)$ \\
\hline PCL-5 $\geq 31$ & $9(33.3 \%)$ & $5(16.1 \%)$ \\
\hline \multicolumn{3}{|c|}{$\begin{array}{l}\text { PHQ-9: Patient health questionnaire-9, GAD-7: Generalized anxiety disorder-7, } \\
\text { PHQ-15: Patient health questionnaire-15, PCL-5: Posttraumatic stress disorder } \\
\text { checklist for DSM-5 }\end{array}$} \\
\hline
\end{tabular}

positive correlation in native patients $(r=0.384, p<0.01)$. The data on the correlates of PHQ-9, GAD-7 and PCL-5 are provided Table 4.

\section{Discussion}

This study aims to investigate and compare the levels of depression, anxiety and PTSD symptoms of refugee and native HD patients during COVID-19. The main findings of the study are as follows: (i) refugee HD patients had similar sociodemographic, clinical and HD characteristics to native patients native patients; (ii) regarding the comparison of the PHQ-SADS subscales scores; anxiety and traumatic stress levels were significantly higher in refugee patients while depression and somatic anxiety levels did not differ among groups; (iii) regarding psychiatric comorbidity; anxiety and PTSD were more frequent among refugee patients and depression was more frequent among native patients; (iv) the age was negatively correlated with depressive symptom levels in the refugee group, while somatic symptom levels were positively correlated with depression, anxiety and PTSD symptom levels among both refugee and native patients.

In a multicenter study conducted in Europe, refugees were found to represent $1.5 \%$ of the dialysis population in several European and Middle Eastern countries with a very skewed geographic distribution, and only a limited number of centers treat $>20$ refugees due to non-reimbursement of the treatment costs (24). In Turkey, all health expenditures of refugees who are under legal "temporary protection" were covered by the Government of The Republic of Turkey. This was probably the main reason of the relatively higher rate of refugee HD patients in our sample. Language and social work assistance for refugee patients in University of Health Sciences Turkey, Haseki Training and Research Hospital could also have contributed to the increased admission rates of the refugees to the HD center of the hospital.

When the rate of participants by gender was examined, the rate of women and men was found to be equal. The majority of the HD patients were middle-aged and with low household income per capita according to the "Income and Living Conditions Survey" of the Turkish Statistical Institute (25). The most common causes of ESRD were diabetic kidney diseases and hypertensive nephrosclerosis as previously reported in other countries and Turkey $(16,26)$. Our results indicated that there was no significant difference regarding sociodemographic, clinical and HD characteristics regarding age, gender, education level, among refugee and native patients.

The presence of comorbid psychiatric disorders in HD patients is a challenging condition for nephrologists as it negatively influences treatment compliance and is 
Yalcin et al. Mental Health of Refugee Dialysis Patients

\begin{tabular}{|c|c|c|c|c|c|c|c|c|c|c|c|c|}
\hline & \multicolumn{4}{|l|}{ PHQ-9 } & \multicolumn{4}{|l|}{ GAD-7 } & \multicolumn{4}{|l|}{ PCL-5 } \\
\hline & \multicolumn{2}{|c|}{$\begin{array}{l}\text { Refugee patients } \\
(\mathrm{n}=27)\end{array}$} & \multicolumn{2}{|c|}{$\begin{array}{l}\text { Native patients } \\
(\mathrm{n}=31)\end{array}$} & \multicolumn{2}{|c|}{$\begin{array}{l}\text { Refugee patients } \\
(\mathrm{n}=27)\end{array}$} & \multicolumn{2}{|c|}{$\begin{array}{l}\text { Native patients } \\
(\mathrm{n}=31)\end{array}$} & \multicolumn{2}{|c|}{$\begin{array}{l}\text { Refugee patients } \\
(n=27)\end{array}$} & \multicolumn{2}{|c|}{$\begin{array}{l}\text { Native patients } \\
(n=31)\end{array}$} \\
\hline & $\mathbf{r}$ & $p$ & $\mathbf{r}$ & $p$ & $\mathbf{r}$ & p & $r$ & p & $\mathbf{R}$ & $p$ & $\mathbf{r}$ & $\mathbf{p}$ \\
\hline Age & -0.611 & $<0.01$ & -0.175 & 0.37 & -0.316 & 0.16 & -0.192 & 0.31 & -0.169 & 0.44 & -0.347 & 0.08 \\
\hline $\begin{array}{l}\text { Monthly household income } \\
\text { per capita }\end{array}$ & -0.019 & 0.93 & -0.316 & 0.25 & 0.007 & 0.98 & -0.083 & 0.75 & -0.205 & 0.38 & -0.299 & 0.30 \\
\hline Duration of HD & 0.171 & 0.46 & 0.080 & 0.68 & -0.030 & 0.89 & 0.054 & 0.78 & -0.037 & 0.87 & -0.059 & 0.77 \\
\hline Duration of refugee status & 0.475 & 0.03 & - & - & 0.264 & 0.25 & - & - & 0.197 & 0.40 & - & - \\
\hline $\mathrm{Kt} / \mathrm{V}$ & 0.173 & 0.45 & 0.057 & 0.77 & -0.030 & 0.89 & -0.005 & 0.98 & -0.212 & 0.33 & -0.126 & 0.53 \\
\hline Albumin & 0.366 & 0.10 & -0.002 & 0.99 & 0.079 & 0.73 & 0.145 & 0.45 & -0.063 & 0.78 & -0.022 & 0.92 \\
\hline Hemoglobin & 0.011 & 0.96 & -0.320 & 0.09 & 0.017 & 0.94 & -0.060 & 0.75 & -0.266 & 0.21 & -0.226 & 0.26 \\
\hline Urea & 0.222 & 0.33 & 0.076 & 0.69 & -0.107 & 0.64 & 0.276 & 0.14 & -0.179 & 0.415 & 0.005 & 0.97 \\
\hline Creatinine & 0.119 & 0.607 & 0.076 & 0.70 & 0.049 & 0.83 & 0.276 & 0.14 & -0.034 & 0.88 & 0.007 & 0.97 \\
\hline Somatic symptoms (PHQ-15) & 0.737 & $<0.001$ & 0.650 & $<0.001$ & 0.600 & $<0.01$ & 0.381 & 0.04 & 0.419 & 0.04 & 0.513 & $<0.01$ \\
\hline
\end{tabular}

r: Spearman's rho correlation coefficient, HD: Hemodialysis, PHQ-9: Patient health questionnaire-9, GAD-7: Generalized anxiety disorder-7, PHQ-15: Patient health questionnaire-15, PCL-5: Posttraumatic stress disorder checklist for DSM-5, Bold print indicates statistical significance at 0.05 level

associated with adverse outcomes such as hospitalization and mortality (27). HD requires regular attendance for several hours per week and dietary restrictions, restricts the patient's autonomy and may lead to a feeling of being machine-dependent. These conditions commonly result in exacerbation of the comorbid psychiatric disorders such as depression and anxiety as well as the emergence of new-onset mental conditions (28). Furthermore, patients with ESRD were found to have higher prevalence rates of depression than those with other chronic diseases (29). When it comes to the nationality and refugee status; in a recent study, the authors have reported that adverse clinical outcomes associated with depressive symptoms differ among ethnic groups, and ethnicity is suggested to be an important factor that could influence the adverse clinical outcomes and depression in HD patients (30). Immigrant HD patients were reported to be more prone to develop depressive and anxiety symptoms than the native patients (31). Accordingly, authors from Jordan have reported that among Syrian refugees with HD dependent ESRD; 36\% had severe depression, 74\% were anxious about their illness and $43 \%$ had feelings of being a burden to their families (17). In another very recent study conducted in Turkey, it was reported that Syrian refugee HD patients had higher depressive symptom levels compared to native HD patients (16). Our results indicated that our sample had higher rates of anxiety, depression and somatic anxiety. The most frequent psychiatric conditions were somatic anxiety and PTSD in refugee patients, while one-third of native patients reported moderate or higher depressive symptoms. Our results indicated similar depression and anxiety levels in HD patients compared to the literature $(2,28,32)$. However, on the contrary to the results of previous studies conducted in Turkey and other countries reporting higher depression levels in refugee populations $(16,31,33)$, depression rates were lower in refugee patients than in native patients. This discrepancy probably resulted from the different methodology of these studies, and it could be explained as follows: (i) different self-report scales with different sensitivity and specificity levels such as Beck depression inventory and hospital anxiety and depression scale were used by the researchers in some of these studies and this could be associated with the discrepancy of the rates of depression; (ii) in our study, we used the cut-off values $\geq 10$ for PHQ-9 indicating moderate or higher depression severity and did not take into account those with mild symptoms in order to obtain more accurate rates of depression, (iii) these studies were conducted in different countries and psychiatric symptom levels of refugees could vary according to the host country (12).

The somatic symptoms of depressive disorders have similar characteristics with the symptoms of uremia such as sleep disturbances, fatigue, anorexia, gastrointestinal symptoms, aspects of volume overload and pain, which may complicate complicate recognizing the underlying psychiatric illness (34). Somatic symptoms and distress are also associated with mental disorders, particularly in the refugee population facing traumatic experiences and economic difficulties, which was also the case in our sample $(13,35)$. Hence, investigating somatic distress in both native and refugee HD patients appears to appers to provide substantial benefit for the detection and management of the mental disorders, and also psychological trauma following humanitarian crises. Besides, patients receiving HD were also found to have higher somatic complaints 
than the general population (36). In our study, onethird of the participants reported moderate or higher somatization and refugee patients had significantly higher levels of somatic symptoms than native patients and this was consistent with studies conducted in Turkey and other countries $(14,37,38)$.

Somatic complaints and distress are also closely associated with psychological trauma and PTSD was previously reported to be a frequent mental health issue among Syrian refugees in Turkey $(13,39)$. Accordingly, in our study, the comparison of PTSD symptom levels revealed that refugee HD patients were having significantly higher PTSD levels than native patients, as expected. As this study is conducted during COVID-19, the pandemic could be another factor which has contributed to the exacerbation of PTSD and somatic distress as previously reported $(40,41)$. These results suggest that HD dependent refugee ESRD patients may be at high risk of somatic anxiety which is associated with the disease itself and psychological trauma.

The age was found to be negatively associated with levels of depression in refugee patients with ESRD in our study. Younger age is reported to be associated with higher depression levels in patients receiving HD (42). However, there are contradictory findings in the literature on the association of the age with psychiatric symptoms among refugee and native HD populations $(13,43,44)$. This discrepancy was probably associated with the different life conditions of refugees in host countries where these studies were conducted. Another explanation is that, the high risk of depression for younger populations populations could be resulted from the negative impact of COVID-19 and related preventive measures on social life, and this probably is also the case for the younger patients with $\operatorname{ESRD}(40,45,46)$. The duration of refugee status was positively correlated with levels of depression, and this result suggests that being under refugee status for a longer duration with a chronic illness such as ESRD could be associated with higher depression levels. Somatic symptoms correlated with depression, anxiety and PTSD levels in both refugee and native patient groups. Individuals with comorbid depression and anxiety are at high risk for somatic symptoms (47). As a considerable amount of the refugees have experienced traumatic events, traumatization may also be an important etiologic factor for somatization in the refugee population. Regarding HD characteristics, laboratory levels of the parameters such as $\mathrm{Kt} / \mathrm{V}$, hemoglobin, albumin, urea and creatinine did not correlate with PHQ-9, GAD-7 and PCL-5 scores.

\section{Study Limitations}

Our study is conducted in a single center and has a relatively small sample size. Thus, the findings of this study cannot be generalized. Due to the cross-sectional design, the effect of the psychiatric conditions on the outcomes of HD could not be investigated. The psychological assessment was conducted via self-rating scales instead of clinical interviews and this may have resulted in increased levels of psychiatric symptoms. Finally, refugee patients in our sample were only registered refugees, and our results does not represent the unregistered Syrian refugees with ESRD which may have higher psychiatric symptom levels and probably could not reach the HD treatment. However, given the growing concerns about the mental health of refugees around the world, our study may contribute to the literature as it is one of the first studies focusing on the mental health of refugee patients with ESRD which may cause a significant psychological burden.

\section{Conclusion}

Our results indicated a high rate of comorbidity of psychiatric conditions in ESRD patients receiving HD, refugee patients appear to have higher comorbidity of anxiety, somatization and PTSD than native HD patients. Hence, refugee HD patients should be closely monitored in terms of psychiatric symptoms. Therefore, routine psychiatric assessment of these patients in order to achieve early diagnosis and more effective management, may contribute to improve the mental health and prevent adverse health outcomes in HD patients. Policy-makers should promote the implementation of formal screening programs for psychiatric disorders among ESRD patients receiving HD. Physicians, nurses and social workers of HD centers should be trained and supported in order to recognize psychiatric symptoms and disorders and to provide psychoeducation programs for the patients and their relatives. HD centers should establish a solid collaboration with consultation-liaison psychiatrists.

\section{Authorship Contributions}

Concept: M.Y., Design: M.Y., E.C., Data Collection or Processing: Y.B., Analysis or Interpretation: M.Y., E.C., S.A., H.K., Literature Search: M.Y., S.A., H.K., Writing: M.Y. Y.B.

Conflict of Interest: No conflict of interest was declared by the authors.

Financial Disclosure: The authors declared that this study received no financial support.

\section{References}

1. Cukor D, Peterson RA, Cohen SD, Kimmel PL. Depression in end-stage renal disease hemodialysis patients. Nat Clin Pract Nephrol 2006;2:678-87.

2. Gerogianni G, Lianos E, Kouzoupis A, Polikandrioti M, Grapsa E. The role of socio-demographic factors in depression and anxiety of patients on hemodialysis: an observational crosssectional study. Int Urol Nephrol 2018;50:143-54.

3. Schouten RW, Haverkamp GL, Loosman WL, et al. Anxiety Symptoms, Mortality, and Hospitalization in Patients 
Receiving Maintenance Dialysis: A Cohort Study. Am J Kidney Dis 2019;74:158-66.

4. Delgado-Domínguez CJ, Sanz-Gómez S, López-Herradón A, et al. Influence of Depression and Anxiety on Hemodialysis Patients: The Value of Multidisciplinary Care. Int J Environ Res Public Health 2021;18:3544.

5. Farrokhi F, Abedi N, Beyene J, Kurdyak P, Jassal SV. Association between depression and mortality in patients receiving longterm dialysis: A systematic review and meta-analysis. Am J Kidney Dis 2014;63:623-35.

6. Al-Nashri F, Almutary $\mathrm{H}$. Impact of anxiety and depression on the quality of life of haemodialysis patients. J Clin Nurs 2021.

7. Kämpfen F, Kohler IV, Ciancio A, et al. Predictors of mental health during the Covid-19 pandemic in the US: Role of economic concerns, health worries and social distancing. PLoS One 2020;15:e0241895.

8. Tull MT, Edmonds KA, Scamaldo KM, Richmond JR, Rose JP, Gratz KL. Psychological Outcomes Associated with Stay-atHome Orders and the Perceived Impact of COVID-19 on Daily Life. Psychiatry Res 2020;289:113098.

9. Silove $D$, Ventevogel $P$, Rees $S$. The contemporary refugee crisis: an overview of mental health challenges. World Psychiatry 2017;16:130-9.

10. Oner O, Kahilogullari AK, Acarlar B, Malaj A, Alatas E. Psychosocial and cultural needs of children with intellectual disability and their families among the Syrian refugee population in Turkey. J Intellect Disabil Res 2020;64:644-56.

11. Hodes M, Anagnostopoulos D, Skokauskas N. Challenges and opportunities in refugee mental health: clinical, service, and research considerations. Eur Child Adolesc Psychiatry 2018;27:385-8.

12. Cheung Chung M, AlQarni N, AlMazrouei M, et al. The impact of trauma exposure characteristics on post-traumatic stress disorder and psychiatric co-morbidity among Syrian refugees. Psychiatry Res 2018;259:310-5.

13. Acarturk C, McGrath M, Roberts B, et al. Prevalence and predictors of common mental disorders among Syrian refugees in Istanbul, Turkey: a cross-sectional study. Soc Psychiatry Psychiatr Epidemiol 2021;56:475-84.

14. McGrath M, Acarturk C, Roberts B, et al. Somatic distress among Syrian refugees in Istanbul, Turkey: A cross-sectional study. J Psychosom Res 2020;132:109993.

15. Godinic D, Obrenovic B, Khudaykulov A. Effects of Economic Uncertainty on Mental Health in the COVID-19 Pandemic Context: Social Identity Disturbance, Job Uncertainty and Psychological Well-Being Model. Int J Innov Econ Dev 2020;6:61-74.

16. Sevinc M, Hasbal NB, Sakaci T, et al. Frequency of depressive symptoms in Syrian refugees and Turkish maintenance hemodialysis patients during COVID-19 pandemic. PLoS One 2021;16:e0244347.
17. Isreb MA, Kaysi S, Rifai AO, Al Kukhun H, Al-Adwan SAS, Kass-Hout TA, Sekkarie MA. The Effect of War on Syrian Refugees With End-Stage Renal Disease. Kidney Int Rep 2017:26;2:960-3.

18. Kroenke K, Spitzer RL, Williams JBW, Löwe B. The Patient Health Questionnaire Somatic, Anxiety, and Depressive Symptom Scales: A systematic review. Gen Hosp Psychiatry 2010;32:345-59.

19. Yazici Güleç $M$, Güleç $H$, Şimşek G, Turhan M, Aydin Sünbül E. Psychometric properties of the Turkish version of the Patient Health Questionnaire-Somatic, Anxiety, and Depressive Symptoms. Compr Psychiatry 2012;53:623-9.

20. AlHadi AN, AlAteeq DA, Al-Sharif E, et al. An arabic translation, reliability, and validation of Patient Health Questionnaire in a Saudi sample. Ann Gen Psychiatry 2017;16:32.

21. Blevins CA, Weathers FW, Davis MT, Witte TK, Domino JL. The Posttraumatic Stress Disorder Checklist for DSM-5 (PCL-5): Development and Initial Psychometric Evaluation. J Trauma Stress 2015;28:489-98.

22. Ibrahim H, Ertl V, Catani C, Ismail AA, Neuner F. The validity of Posttraumatic Stress Disorder Checklist for DSM-5 (PCL5) as screening instrument with Kurdish and Arab displaced populations living in the Kurdistan region of Iraq. BMC Psychiatry 2018;18:259.

23. Boysan M, Ozdemir PG, Ozdemir O, Selvi Y, Yilmaz E, Kaya N. Psychometric properties of the Turkish version of the PTSD Checklist for Diagnostic and Statistical Manual of Mental Disorders, Fifth Edition (PCL-5). Psychiatry Clin Psychopharmacol 2017;27:300-10.

24. Van Biesen W, Vanholder R, Vanderhaegen B, et al. Renal replacement therapy for refugees with end-stage kidney disease: an international survey of the nephrological community. Kidney Int 2016 Suppl 2011 2016;6:35-41.

25. TÜiK. Türkiye İstatistik Kurumu. Gelir ve Yaşam Koşulları Araştırması, 2020. Available from: https://data. tuik.gov.tr/Bulten/Index? p=Gelir-ve-Yasam-KosullariArastirmasi-2020-37404

26. Stasiak CE, Bazan KS, Kuss RS, Schuinski AF, Baroni G. Prevalence of anxiety and depression and its comorbidities in patients with chronic kidney disease on hemodialysis and peritoneal dialysis. J Bras Nefrol 2014;36:325-31.

27. Goh ZS, Griva K. Anxiety and depression in patients with endstage renal disease: impact and management challenges - a narrative review. Int J Nephrol Renovasc Dis 2018;11:93-102.

28. Marthoenis M, Syukri M, Abdullah A, et al. Quality of life, depression, and anxiety of patients undergoing hemodialysis: Significant role of acceptance of the illness. Int J Psychiatry Med 2021;56:40-50.

29. Kimmel PL, Thamer M, Richard CM, Ray NF. Psychiatric illness in patients with end-stage renal disease. Am J Med 1998; 105:214-21. 
30. Schouten RW, Haverkamp GL, Loosman WL, et al. Ethnic Differences in the Association of Depressive Symptoms with Clinical Outcome in Dialysis Patients. J Racial Ethn Heal Disparities 2019;6:990-1000.

31. Loosman WL, Haverkamp GLG, van den Beukel TO, et al. Depressive and Anxiety Symptoms in Dutch Immigrant and Native Dialysis Patients. J Immigr Minor Health 2018;20:133946.

32. Mosleh H, Alenezi M, Johani SAl, Alsani A, Fairaq G, Bedaiwi R. Prevalence and Factors of Anxiety and Depression in Chronic Kidney Disease Patients Undergoing Hemodialysis: A Cross-sectional Single-Center Study in Saudi Arabia. Cureus 2020;12:e6668.

33. Missinne S, Bracke P. Depressive symptoms among immigrants and ethnic minorities: a population based study in 23 European countries. Soc Psychiatry Psychiatr Epidemiol 2010;47:97-109.

34. Kimmel PL, Peterson RA. Depression in Patients with EndStage Renal Disease Treated with Dialysis: Has the Time to Treat Arrived? Clin J Am Soc Nephrol 2006;1:349-52.

35. Morina N, Ford JD, Risch AK, Morina B, Stangier U. Somatic distress among Kosovar civilian war survivors: relationship to trauma exposure and the mediating role of experiential avoidance. Soc Psychiatry Psychiatr Epidemiol 2010;45:116777.

36. Lou X, Li Y, Shen H, Juan J, He Q. Physical activity and somatic symptoms among hemodialysis patients: a multi-center study in Zhejiang, China. BMC Nephrol 2019;20:477.

37. Bagayogo IP, Interian A, Escobar JI. Transcultural Aspects of Somatic Symptoms in the Context of Depressive Disorders. Adv Psychosom Med 2013;33:64-74.

38. Nesterko $Y$, Jäckle $D$, Friedrich $M$, Holzapfel L, Glaesmer $H$. Prevalence of post-traumatic stress disorder, depression and somatisation in recently arrived refugees in Germany: an epidemiological study. Epidemiol Psychiatr Sci 2020;29:40.
39. Alpak G, Unal A, Bulbul F, et al. Post-traumatic stress disorder among Syrian refugees in Turkey: A cross-sectional study. Int J Psychiatry Clin Prct 2015;19:45-50.

40. Goularte JF, Serafim SD, Colombo R, Hogg B, Caldieraro MA, Rosa AR. COVID-19 and mental health in Brazil: Psychiatric symptoms in the general population. J Psychiatr Res 2021;132:32-7.

41. Liu CH, Zhang E, Wong GTF, Hyun S, Hahm HC. Factors associated with depression, anxiety, and PTSD symptomatology during the COVID-19 pandemic: Clinical implications for U.S. young adult mental health. Psychiatry Res 2020;290:113172.

42. Muthukumaran A, Natarajan G, Thanigachalam D, Sultan SA, Jeyachandran D, Ramanathan S. The Role of Psychosocial Factors in Depression and Mortality Among Urban Hemodialysis Patients. Kidney Int Rep 2021;6:1437-43.

43. Chung MC, AlQarni N, AlMazrouei M, et al. Posttraumatic Stress Disorder and Psychiatric Co-morbidity among Syrian Refugees of Different Ages: the Role of Trauma Centrality. Psychiatr Q 2018;89:909-21.

44. Nickerson A, Schick M, Schnyder U, Bryant RA, Morina N. Comorbidity of Posttraumatic Stress Disorder and Depression in Tortured, Treatment-Seeking Refugees. J Trauma Stress 2017;30:409-15.

45. Shevlin M, McBride O, Murphy J, et al. Anxiety, depression, traumatic stress and COVID-19-related anxiety in the UK general population during the COVID-19 pandemic. BJPsych Open 2020;6:125.

46. Cansel N, Ucuz I, Arslan AK, et al. Prevalence and predictors of psychological response during immediate COVID-19 pandemic. Int J Clin Pract 2021;75:e13996.

47. Niles $A N$, Dour HJ, Stanton AL, et al. Anxiety and Depressive Symptoms and Medical Illness Among Adults with Anxiety Disorders. J Psychosom Res 2015;78:109-15. 